\title{
Comparison of syntax score and syntax score II to predict peri-procedural myocardial injury during percutaneous coronary intervention
}

Adil Bayramoğlu ( $\square$ adilbayramoglu@gmail.com )

İnönü Üniversitesi: Inonu Universitesi https://orcid.org/0000-0002-6523-9130

Şı ho Hidayet

İnönü University

Seçkin Dereli

Ordu University

Original Article

Keywords: peri-procedural injury, syntax score , syntax score II

Posted Date: February 9th, 2021

DOl: https://doi.org/10.21203/rs.3.rs-196592/v1

License: (c) (i) This work is licensed under a Creative Commons Attribution 4.0 International License.

Read Full License 


\section{Abstract \\ Background}

Peri-procedural myocardial infarction(PPI) is an increase in cardiac enzymes during percutaneous coronary intervention. The development of this condition is associated with a poor prognosis. In this study, we aimed to evaluate the development of PPI in patients undergoing elective percutaneous coronary intervention and the factors that predict patients who developed PPI.

\section{Method:}

A total of 160 consequtive patients who underwent percutaneous coronary intervention were enrolled in the study. Patients were divided into two groups as PPI developing and not developing PPI. The clinical characteristics, laboratory and angiographic features of groups were compared. The SS and SS II was calculated by using the online calculator.

\section{Results}

PPI was devoloped in 44 (27.5\%) patients during PCI procedure. SS ,SSII, glomerular filtration rate (GFR), age were identified as independent predictors of PPI. A higher rate of PPI was observed in those with SSII over 35. When compaired of the ROC curves showed that area under curve of SS II was larger than that of SS (AUC 0.855 vs. $0.741, p=0.039$ )

\section{Conclusion}

In the study; age GFR, SS and SSII were observed to be independent predictors of PPI. SSII may be a more useful tool than SS for prediction PPI during elective percutaneous coronary intervention.

\section{Introduction}

Peri-procedural myocardial injury (PPI) is a common situation during percutaneous coronary intervention (PCI) $[1,2]$. PPI can be caused by plaque shift, side branch occlusion, microvascular injury due to distal embolization during PCl procedure[3]. Studies have shown that even small elevations in cardiac biochemical markers are associated with poor clinical outcomes[4]. Therefore, studies have been conducted on various markers for prediction of PPI, which may develop prior to the procedure.

Syntax score (SS) is an anatomic and morphologic scoring system that quantitatively characterizes coronary vasculature according to the complexity of obstructive coronary lesions. [5, 6]. The syntax score which is used to describe the severity of coronary artery disease (CAD) predicts post-PCl events[7]. The syntax score II is a newer scoring system used to show the survey of patients directed to coronary artery 
bypass greft (CABG) or PCI [6]. Although the association between the complexity-severity of CAD and PPI has been shown[8]. The relationship between SS II and SS in patients with PPI hasn't been studied yet.

We aimed to investigate the association between PPI and SS, SS II, in patients with stable CAD who underwent $\mathrm{PCl}$.

\section{Method}

In this study, a total of 160 patients with stable CAD who had objective ischemia symptoms and thus, underwent PCI procedure between January 2017 and June 2017, and who were eligible for the study conditions were included. Patients who underwent stent implantation in the lesions over $30 \mathrm{~mm}$ with or without side branches, and those undergone stent implantation providing a side branch of at least $2 \mathrm{~mm}$ in diameter in the case of the the lesions under $30 \mathrm{~mm}$ and the patients who underwent bifurcation procedure were included in this study[9]. Patients who previously underwent stent implantation or CABG, those having unstable angina pectoris, acute coronary syndrome, and which complicated during the procedure due to the development of dissection or no reflow were exluded from the study.

\section{Angiographic and Laboratuary parameters analysis}

The angiography was performed in all patients with a transfemoral approach. $7 \mathrm{Fr}$ catheters were used with the Seldinger method. Patients to undergo PCI procedures were given klopidogrel $(600 \mathrm{mg}), 100 \mathrm{mg}$ ASA and $70 \mathrm{IU} / \mathrm{Kg}$ unfractionated heparin. SS II and SS were calculated using a calculator (http://www.syntaxscore com) (Figure1). Two cardiologists who were blinded to the study evaluated and calculated SS II and SS. In angiograms with conflicting results, both cardiologists evaluated these angiograms a consensus was provided. Any large coronary vessel with a diameter narrowing by 50 percent or more was considered as important stenosis.

\section{Laboratuary analysis}

Blood samples collected at admissions were used for evaluations. The Cockroft-Gault formula was used to calculate the glomerular filtration rate (GFR).

Modified Simpson method was used for left ventricular ejection fraction (EF). All patients gave written or verbal consents. This study protocol was confirmed by the local ethics committee in conformity with the Declaration and Good Clinical Practice guidelines.

Cardiac biomarkers were obtained from venous blood samples that were collected before, at 8-24h and at $24 \mathrm{~h}$ after the procedure. Troponin-I were measured with immunoassays (Abbot Park, IL 60064,USA). PPI was defined by elevation of cTnl values $>5 \times 99$ th percentile upper normal in patients with normal values ( $\leq 99$ th percentile upper normal). In addition, symptoms of myocardial ischaemia or new ischemic electrocardiographic changes or showing a new regional wall motion disnormality are required.

\section{Statistycal analysis}


The data analysis was applied using SPSS software (version 20.0, SPSS Inc. , Chicago, Illinois) and MedCalc Software (12.7.8, Mariakerke, Belgium). Categorical variables compared with the $\chi 2$ or Fisher's exact test was summarized as percentages. Continuous variables were stated as mean \pm Standard deviation.. The Kolmogorov-Smirnov test was used to assess distribution of continuous variables. To predict PPI , age, left main coronary artery, peripheral arterial disease (PAH), chronic obstructive pulmonary disease (COPD), GFR, EF, SS, and SSII were analysed. The parameters with $p<0.05$ were included in the multiple logistic analysis. The cut-off values of SS II and SS for prediction of periprosedural injury were determined by using receiver-operating characteristic (ROC) analysis. Bland Altman test was used for comparation of ROC curves analysis.

\section{Results}

In 44 (27.5\%) patients developed PPI during PCI procedure. Angiographic characteristics, clinical features of groups are shown in Table 1. Age, presence of LMCA disease, GFR, EF, COPD, PAH, SS and SS II were different in two groups. 102 patients had SSII $<35$ and 58 had SSII $\geq 35$. There were differences between two groups in age ,heart rate, presence of LMCA disease, GFR, EF, PAH, double vessel PCI and PPI (Table 2). 
Table 1

The baseline clinical characteristics, laboratory, angiographic features of the findings in two groups

\begin{tabular}{|c|c|c|c|}
\hline & $\begin{array}{l}\text { NO PPI } \\
(n=116)\end{array}$ & $\begin{array}{l}\text { PPI } \\
(n=44)\end{array}$ & $\mathbf{p}$ \\
\hline Age (years) & $61.5 \pm 10.5$ & $72.6 \pm 9.15$ & $<0.001$ \\
\hline Sex $($ male $)(n, \%)$ & $34(29.3)$ & $10(22.7)$ & 0.405 \\
\hline Diabetes Mellitus (n,\%) & $44(37.9)$ & $12(27.3)$ & 0.207 \\
\hline Hypertension (n ,\%) & $65(56)$ & $31(70.5)$ & 0.096 \\
\hline Hyperlipidemia (n, \%) & $34(29.3)$ & $14(31.8)$ & 0.757 \\
\hline Smoking (n, \%) & $56(48.3)$ & $21(47.7)$ & 0.951 \\
\hline $\mathrm{SBP}(\mathrm{mmHg})$ & $128.1 \pm 26.9$ & $130.6 \pm 36,3$ & 0.765 \\
\hline $\mathrm{DBP}(\mathrm{mmHg})$ & $74.7 \pm 18.0$ & $75.0 \pm 23.2$ & 0.699 \\
\hline Heart Rate(p/min) & $70.5 \pm 10.2$ & $68.2 \pm 11.1$ & 0.256 \\
\hline Bifurcation lesions & $30(25.8)$ & 17(38.6) & 0.113 \\
\hline Glucose (mg/dL) & $129 \pm 53$ & $123 \pm 57$ & 0.464 \\
\hline LDL-C (mg/dL) & $123.3 \pm 35.6$ & $131.8 \pm 33.1$ & 0.174 \\
\hline $\mathrm{HDL}-\mathrm{C}(\mathrm{mg} / \mathrm{dL})$ & $41.6 \pm 9.6$ & $39.0 \pm 7.9$ & 0.113 \\
\hline $\mathrm{TG}(\mathrm{mg} / \mathrm{dL})$ & $186.5 \pm 32.2$ & $176.2 \pm 35,6$ & 0.083 \\
\hline LMCA (n ,\%) & $8(6.9)$ & $10(22.7)$ & 0.005 \\
\hline $\mathrm{GFR}(\mathrm{mL} / \mathrm{min} / 1.73 \mathrm{~m} 2)$ & $102.0 \pm 21.5$ & $84.8 \pm 24.8$ & $<0.001$ \\
\hline $\mathrm{EF}(\%)$ & $54.6 \pm 6.1$ & $48.7 \pm 8.1$ & $<0.001$ \\
\hline COPD & 13(11.2) & 12(27.3) & 0.012 \\
\hline PAD & 10(8.6) & 18(40.9) & $<0.001$ \\
\hline Double-vessel PCI & $18(15.5)$ & $12(27.3)$ & 0.089 \\
\hline Syntax score & $19.5 \pm 7.4$ & $27.0 \pm 8.8$ & $<0.001$ \\
\hline Syntax score II & $29.7 \pm 7.8$ & $44.8 \pm 9.6$ & $<0.001$ \\
\hline LAD & $43(37.1)$ & $10(22.7)$ & \multirow[t]{2}{*}{0.227} \\
\hline$c X$ & $41(35.3)$ & $19(43.2)$ & \\
\hline $\begin{array}{l}\text { LMCA: Left Main Corona } \\
\text { coronary artety, PAD: peri } \\
\text { Ejection Fractione }\end{array}$ & $\begin{array}{l}\text { eft ascending } \\
\text { sease, CAPD: }\end{array}$ & $\begin{array}{l}\text { : Circumflexia } \\
\text { ostructive Pul }\end{array}$ & $\begin{array}{l}\text { A: Right } \\
\text { sease, EF }\end{array}$ \\
\hline
\end{tabular}




\begin{tabular}{|l|ll|}
\hline & $\begin{array}{l}\text { NO PPI } \\
(\mathbf{n = 1 1 6 )}\end{array}$ & $\begin{array}{l}\text { PPI } \\
(\mathbf{n = 4 4 )}\end{array}$ \\
\hline RCA & $32(27.6)$ & $15(34.1)$ \\
\hline $\begin{array}{l}\text { LMCA: Left Main Coronary Artery, LAD: Left ascending artery, CX: Circumflexial artery, RCA: Right } \\
\text { coronary artety, PAD: peripheral artery disease, CAPD: Chronic Obstructive Pulmonary Disease, EF: } \\
\text { Ejection Fractione }\end{array}$ & \\
\hline
\end{tabular}

Table 2

The baseline clinical and laboratory characteristics of the patients according to SS II subgroups

\begin{tabular}{|llll|}
\hline & $\begin{array}{l}\text { SS II<35 } \\
(\mathbf{n = 1 0 2})\end{array}$ & $\begin{array}{l}\text { SS II>35 } \\
(\mathbf{n = 5 8})\end{array}$ & $\mathbf{p}$ \\
\hline Age (years) & $60.4 \pm 10.1$ & $71.8 \pm 9.5$ & $<0.001$ \\
\hline Sex, female (n, \%) & $24(23.5)$ & $20(34.5)$ & 0.136 \\
\hline Diabetes Mellitus (n, \%) & $33(32.4)$ & $23(39.7)$ & 0.352 \\
\hline Hypertension (n, \%) & $53(52)$ & $43(74.1)$ & 0.006 \\
\hline Hyperlipidemia (n, \%) & $28(27.5)$ & $20(34.5)$ & 0.351 \\
\hline Smoking (n, \%) & $52(51)$ & $25(43.1)$ & 0.338 \\
\hline Heart Rate (p/min) & $70.3 \pm 10.8$ & $65.0 \pm 9.9$ & 0.002 \\
\hline Glucose (mg/dL) & $121 \pm 49$ & $139 \pm 60$ & 0.056 \\
\hline LDL-C (mg/dL) & $125.0 \pm 35.5$ & $126.8 \pm 34.5$ & 0.758 \\
\hline HDL-C (mg/dL) & $41.7 \pm 9.7$ & $39.4 \pm 8.2$ & 0.142 \\
\hline TG (mg/dL) & $184.2 \pm 32.0$ & $182.6 \pm 35,6$ & 0.762 \\
\hline LMCA disease & $3(2.9)$ & $15(25.9)$ & $<0.001$ \\
\hline GFR (mL/min/1.73 m2) & $108.3 \pm 18.9$ & $77.9 \pm 18.3$ & $<0.001$ \\
\hline Ejection Fraction (\%) & $55.8 \pm 5.2$ & $48.0 \pm 7.5$ & $<0.001$ \\
\hline COPD (n, \%) & $12(11.8)$ & $13(22.4)$ & 0.075 \\
\hline PAD (n, \%) & $6(5.9)$ & $22(37.9)$ & $<0.001$ \\
\hline Double-vessel PCl (n, \%) & $8(7.8)$ & $22(37.9)$ & $<0.001$ \\
\hline Peri-prosedural injury (n,\%) & $11(10.8)$ & $33(59.6)$ & \\
\hline LDL-C low-density lipoprotein cholesterol, & HDL-C: high-density & lipoprotein cholesterol, & TG: triglyceride, \\
\hline GFR: glomerular filtration rate, LMCA: left main coronary artery, PAD: peripheral arterial disease, & \\
\hline COPD: chronic obstructive pulmonary disease, EF: ejection fraction, & & \\
\hline & & & \\
\hline
\end{tabular}


In the univariate analysis Age, COPD, LMCA disease, PAD, GFR, EF, SS, SSIl found to be significant for PPI. In multivariate analysis ;Age ( [OR] = 1.071, 95\% [Cl]:1.006-1.140,P = 0.031), GFR ( [OR] = $1.056[\mathrm{Cl}]: 1.015-$ $1.095, \mathrm{P}=0.007)$, SS ([OR] = 1.075 [Cl]: 1.003-1.153, $\mathrm{P}=0.042)$, and SS II ( [OR] = $1.176[\mathrm{Cl}]: 1.082-1.278$, $P<0.001$ ) were found independent predictors for PPI ( Table 3).

Table 3

Univariate and Multivariate Analysis for Peri Procedural Injury

\begin{tabular}{|llllll|}
\hline & \multicolumn{4}{l}{ Univariate analysis } & \multicolumn{3}{l|}{ Multivariate analysis } \\
\cline { 2 - 6 } & OR, 95\%Cl & P value & OR & $95 \%$ Cl & P value \\
\hline Age & $1.117(1.070-1.166)$ & $<0.001$ & 1.071 & $1.006-1.140$ & 0.031 \\
\hline COPD & $0.337(0.140-0.811)$ & 0.012 & & & \\
\hline LMCA & $0.252(0.092-0.689)$ & 0.005 & & & \\
\hline PAD & $0.136(0.056-0.330)$ & $<0.001$ & & & 0.007 \\
\hline GFR & $0.966(0.950-0.983)$ & $<0.001$ & 1.054 & $1.015-1.095$ & \\
\hline EF & $0.893(0.848-0.941)$ & $<0.001$ & & & 0.042 \\
\hline Syntax score & $1.105(1.056-1.156)$ & $<0.001$ & 1.075 & $1.003-1.153$ & $<0.001$ \\
\hline Syntax Score II & $1.123(1.079-1.168)$ & $<0.001$ & 1.176 & $1.082-1.278$ & \\
\hline $\begin{array}{l}\text { GFR: glomerular filtration rate, LMCA: left main coronary artery, PAD: peripheral arterial disease, } \\
\text { COPD: chronic obstructive pulmonary disease, EF: ejection fraction, }\end{array}$ \\
\hline
\end{tabular}

ROC curve was carried out in order to determine the best cut off value for SSII and SS in prediction of PPI. The optimal threshold point of SS in the prediction of PPI was $>22$, with $68.1 \%$ specificity and $79.5 \%$ sensitivity (AUC: $0.741,95 \% \mathrm{Cl}: 0.650-0.833, P<0.001$ ). The optimal threshold point of SS II in the prediction of PPI was $>35$, with $75.0 \%$ specificity and $79.5 \%$ sensitivity ( AUC: $0.8551,95 \% \mathrm{Cl}$ : $0.795-$ $0.916, P<0.001)$. Comparing the ROC curves showed that SSII is a better PPI predictor than SS $(0.855$ vs $0.741, p=0.039$ ) (Fig. 2).

\section{Discussion}

In the study, we aimed to assess the effects of SS and SSII on the development of PPI in patients who undergo PCI procedure. In our work, the SSII was shown to be superior to the SS in predicting the development of PPI in patients with stable coronary artery disease who underwent elective PCI procedure.

PPI development after PCl is a very common situation and has prognostic significance[10]. Many studies have shown that even small elevations in enzyme levels following PCI procedure increase risk of death and associated with a worse prognosis[11]. Therefore, determination of the parameters that predicting the development of PPI after PCI may be important in order to prevent development of PPI prior to the procedure, to improve the treatment methods, or in premedication. 
Studies analyzing myocardial involvement such as MR and IVUS have shown that distal embolization or side branch narrowing during the $\mathrm{PCl}$ procedure are two important factors in the development of $\mathrm{PPI}{ }^{9}$. In addition, scorings carried out during angiography have indicated that plaque burden, bifurcation anatomy, and complex lesions predict PPI development[7, 8].

$\mathrm{SS}$ is a risk score designed to be helpful in directing physicians to prefer $\mathrm{CABG}$ or $\mathrm{PCl}$ in patients with triple-vessel disease[5, 6]. In a previous study, SS was shown as a parameter predicting PPI compared to various risk scores[7]. Supporting to the previous study, in our study we found that SS was significantly higher in PPI group.

Studies have shown that PPI development was more common after $\mathrm{PCl}$ procedure in patients with chronic renal failure and that low GFR was an independent predictor of PPI development[12, 13]. Similarly, in our study GFR was to be an independent predictor of PPI development.

Association between multiple vascular disease and COPD has been shown in studies[14, 15]. In a study; have been shown that the patients with COPD who underwent PCI procedure had a higher incidence of myocardial injury [14]. Supporting this, in the present sturdy higher incidence of COPD was observed among the patients who developed PPI. However, according to multivariate analysis, COPD was not an independent predictor.

SS II anatomical is a score developed by adding different parameters to SS, including age, sex, creatinine clearance, peripheral vascular disease, COPD, left ventricular EF, and LMCA disease [17]. In a study by Yesin et al. SSII was shown to be superior to SS in predicting of no reflow pathophysiology of which includes common factors with PPI. In our study, we showed that the association between PPI development and SSII was higher than SS[18]. Parameters such as age, COPD and low GFR are known to be associated with microvascular circulation disorder [19-21]. Because of SS II to include these additional parameters may be partially explain why SSII is PPI.

In conclusion, our study showed that SSII is better than of SS in the predicting of the risk for PPI development. SSII may be considered to be a more useful tool than SS in order to improve the existing treatment that aim improving clinical outcomes for patients with $\mathrm{PCl}$ and to evaluate the new strategies to reduce PPI. However, we believe that it may be beneficial to evaluate this result with further larger studies.

Study limitations:

This study was a single-center study with a small number of patients. In addition, short- and long-term follow-ups of the patients who developed PPI were not performed. As another limitation, patients with unstable angina pectoris and those underwent grafting after CABG were not included in the study.

\section{Declarations}




\section{Acknowledgement}

None

\section{References}

1.Selvanayagam JB, Porto I, Channon K, et al (2005) Troponin elevation after percutaneous coronary intervention directly represents the extent of irreversible myocardial injury: insights from cardiovascular magnetic resonance imaging. Circulation;111(8):1027-32.

2 Abdelmeguid AE, Topol EJ, Whitlow PL et al (1996) Significance of mild transient release of creatine kinase-MB fraction after percutaneous coronary interventions. Circulation 94:1528-36.

3.Porto I, Selvanayagam JB, Van Gaal WJ, et al (2006) Plaque volume and occurrence and location of periprocedural myocardial necrosis after percutaneous coronary intervention: insights from delayedenhancement magnetic resonance imaging, thrombolysis in myocardial infarction myocardial perfusion grade analysis, and intravascular ultrasound. Circulation $114: 662-9$.

4.Ellis SG, Chew D, Chan A, Whitlow PL, Schneider JP, Topol EJ (2002)Death following creatine kinase-MB elevation after coronary intervention: identification of an early risk period: importance of creatine kinaseMB level, completeness of revascularization, ventricular function, and probable benefit of statin therapy. Circulation $106: 1205-10$.

5.Morice MC, Serruys PW, Kappetein AP et al (2010) Outcomes in patients with de novo left main disease treated with either percutaneous coronary intervention using paclitaxel-eluting stents or coronary artery bypass graft treatment in the Synergy Between Percutaneous Coronary Intervention with TAXUS and Cardiac Surgery (SYNTAX) trial. Circulation 121:2645-2653

6.Sianos G, Morel MA, Kappetein AP, et al (2005) The Syntax score: an angiographic tool grading the complexity of coronary artery disease. Eurointervention 1:219-27.

7.William J. van Gaal ,Francis A. Ponnuthurai et al (2009) The Syntax score predicts peri-procedural myocardial necrosis during percutaneous coronary intervention International Journal of Cardiology 135 : $60-65$.

8.Farooq V, van Klaveren D, Steyerberg EW et al (2013) Anatomical and clinical characteristics to guide decision making between coronary artery bypass surgery and percutaneous coronary intervention for individual patients: development and validation of SYNTAX score II. Lancet 381:639-65

9.Porto I, Selvanayagam JB, Van Gaal WJ, et al (2006) Plaque volume and occurrence and location of periprocedural myocardial necrosis after percutaneous coronary intervention: insights from delayedenhancement magnetic resonance imaging, thrombolysis in myocardial infarction myocardial perfusion grade analysis, and intravascular ultrasound. Circulation 114:662-9 
10.Akkerhuis KM, Alexander JH, Tardiff BE, et al(2002) Minor myocardial damage and prognosis: are spontaneous and percutaneous coronary intervention-related events different? Circulation 105:554-6.

11.Simoons ML, van den Brand M, Lincoff M, et al (1999) Minimal myocardial damage during coronary intervention is associated with impaired outcome. Eur Heart J 20:1112-9.

12.Kumagai S, Ishii $\mathrm{H}$, Amano $\mathrm{T}$, Uetani $\mathrm{T}$ et al (2012) Impact of chronic kidney disease on the incidence of peri-procedural myocardial injury in patients undergoing elective stent implantation. Nephrol Dial Transplant. 27:1059-63.

13.Jerkic H, Letilovic T, Stipinovic M, Pocanic D, Catic J, Knotek M(2016) Association of chronic kidney disease with periprocedural myocardial injury after elective stent implantation: A single center prospective cohort study. Medicine(Baltimore). 95:5381.

14.Konecny $\mathrm{T}$, Somers $\mathrm{K}$, Orban $\mathrm{M}$ et al (2010) Interactions between COPD and outcomes after percutaneous coronary intervention. Chest 138:621-627

15.Koseoglu C, Kurmus O, Ertem AG et al (2016)Forced expiratory volume in one second can predict SYNTAX score in patients with chronic obstructive pulmonary disease. Kardiol Pol:74:584-590

16.Wang G, Hua Q, Li J et al (2016) Does SYNTAX score II predict poor myocardial perfusion in STsegment elevation myocardial infarction. Cardiol J 23:317-323.

17. Fukui T, Uchimuro T, Takanashi S (2015) EuroSCORE II with SYNTAX score to assess risks of coronary artery bypass grafting outcomes. Eur J Cardiothorac Surg $47: 66-71$.

17.Yesin M, Çağdaş M, Kalçı M et al (2016) Comparison of syntax score and syntax score II to predict "no reflow phenomenon" in patients with ST-segment elevation myocardial infarction Int J Cardiovasc Imaging 33,1883-1889

19. Osugi N, Suzuki S, Ishii H, Yasuda Y, et al (2014) Impact of albuminuria on the incidence of periprocedural myocardial injury in patients undergoing elective coronary stent implantation. Am J Cardiol.;114:42-6.

120. Chen ZW, Yang HB, Chen YH, Qian JY, Shu XH, Ge JB (2015) The influence of aortic valve calcification on the risk of periprocedural myocardial injury after elective coronary intervention. Aging Clin Exp Res. 27: 631-6.

21.Liang BM, Xu ZB, Yi Q et al (2013) Association of chronic obstructive pulmonary disease with coronary artery disease. Chin Med J 126:3205-3208

\section{Figures}




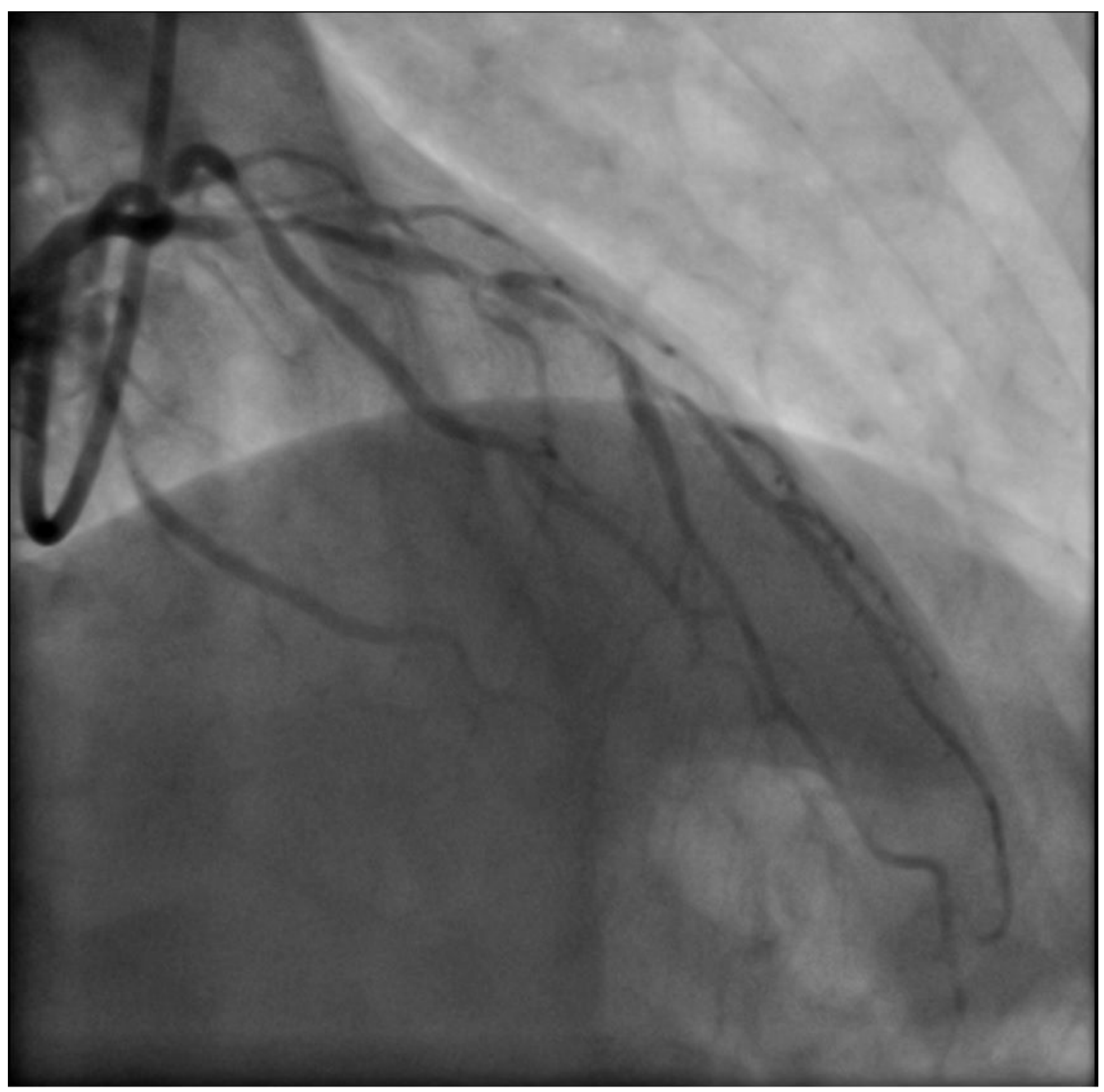

\section{Figure 1}

The left coronary artery system of patiant. Syntax Score $=22$ and Syntax Score II=41.8 ( The Patient's age: 79 ; Creatinine clearance:90 ; LVEF (\%): 45 Gender: Female; Left Main Lesion: No; Chronic Obstrictive Pulmonary Desase: Yes; Peripheral artery Disease: No 


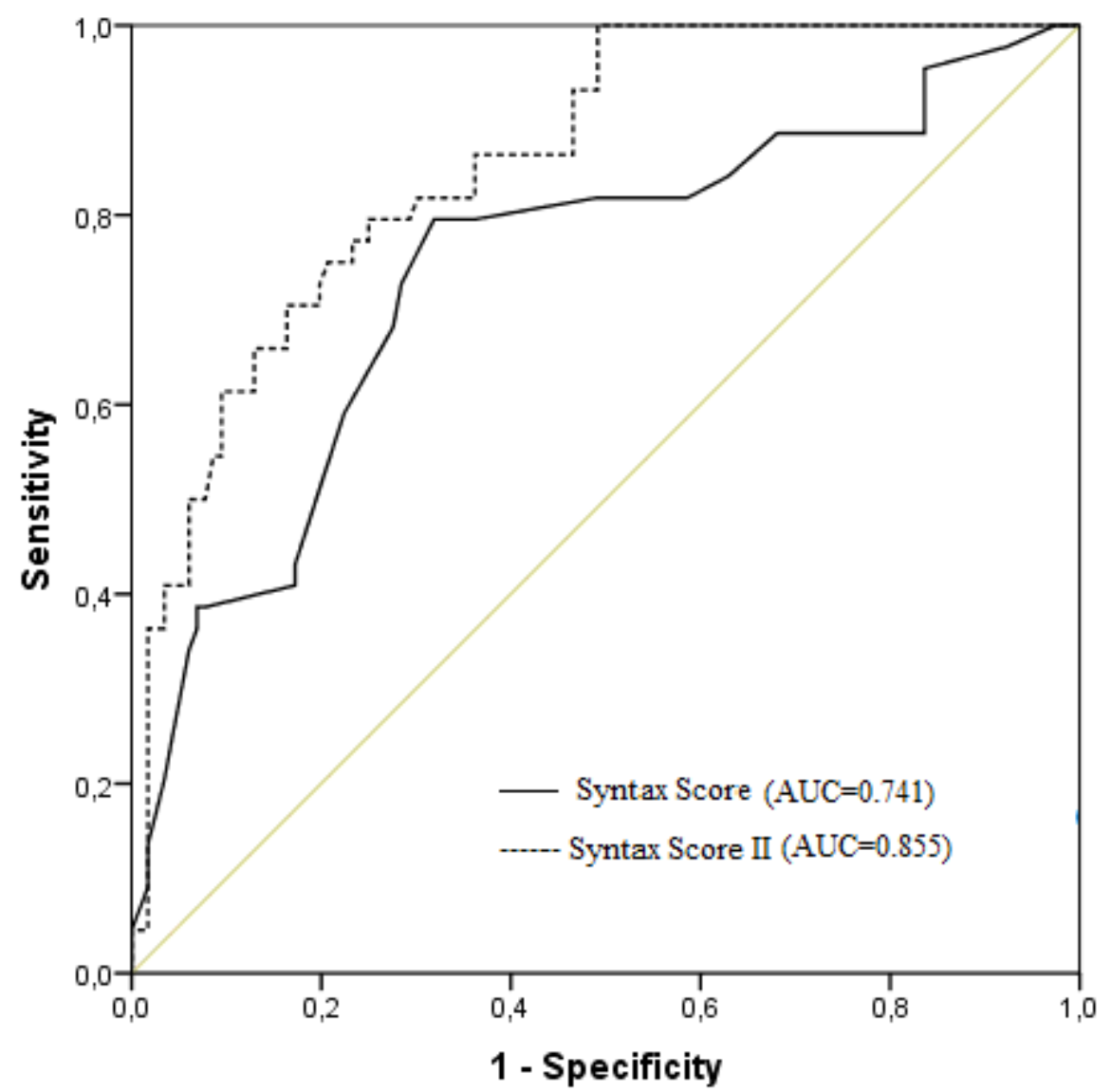

Figure 2

The comparison of the area under the curves (AUC) of ROC curve analyses for syntax score and syntax score II 